\title{
CHARACTERISTICS OF HOTMIX AC-BC WITH NANOGRAPHENE FILLER
}

\author{
Muhammad Shalahuddin \\ Civil Engineering Department, Faculty of Engineering, \\ Riau University, Pekanbaru, Indonesia

\section{Ermiyati} \\ Civil Engineering Department, Faculty of Engineering, \\ Riau University, Pekanbaru, Indonesia

\section{Suprasman} \\ Civil Engineering Department, Faculty of Engineering, \\ Riau University, Pekanbaru, Indonesia

\section{Yenita Morena} \\ Civil Engineering Department, Faculty of Engineering, \\ Riau University, Pekanbaru, Indonesia
}

\begin{abstract}
This study analyzes the influence of the addition of graphene nano-material as filler on asphalt concrete base course (AC-BC). Triple layer on carbon graphene structure serves as a strengthening to improve the stability of hotmix $A C-B C$ significantly. It is important to know how accumulation of graphene nano-material fiber sheet that has a very wide surface $(\mathrm{m} 2 / \mathrm{gr})$ with bitumen. Testing was conducted with a combination of graphene $0 \%, 3.5 \%, 4 \%$, and $4.5 \%$ by asphalt weight. The results showed that addition graphene decreases the penetration of asphalt from $60 \mathrm{~mm}$ to $53.6 \mathrm{~mm}$, decreases the value of optimum asphalt $1.75 \%$, improves stability from $1,260 \mathrm{~kg}$ to $1,480 \mathrm{~kg}$, increase flow / elasticity from $3.80 \mathrm{~mm}$ to $4.50 \mathrm{~mm}$, decrease void in mix (VIM) $10.95 \%$, increases void filled asphalt (VFA) $2.10 \%$, and increases void in mix asphalt (VMA) $3.77 \%$. It is phenomenal that nanographene on AC-BC hotmixs can increase strength while also improving elasticity.
\end{abstract}

Keywords: Graphene, Marshall characteristics, hotmix AC-BC

Cite this Article: Muhammad Shalahuddin, Ermiyati, Suprasman and Yenita Morena, Characteristics of Hotmix AC-BC with Nanographene Filler, International Journal of Civil Engineering and Technology (IJCIET), 12(5), 2021, pp. 29-36. https://iaeme.com/Home/issue/IJCIET?Volume=12\&Issue $=5$ 


\section{INTRODUCTION}

AC-BC forming materials are coarse aggregates, fine aggregates, bitumen and fillers. Marshall characteristics are stability, flow, VFA, VMA, VIM and marshall quotient (MQ).

Graphene is a carbon allotrope consisting of a single layer bonded to a carbon atom. Graphene is used as a reinforcement of composite materials due to their mechanical and thermal properties. The addition of graphene to the Construction Of Porous Asphalt Pavement Using Graphene improved stability by $14.71 \%[1]$. Ranjbar N et al[2] uses graphene nanoplatelet (GNP) as a filler on fly ash-based geopolymers. Bending strength value without GNP was 2.8 $\mathrm{MPa}$ and the increase bending strength in addition to $1 \%$ GNP was $74.24 \%$. Other filler materials such as cement, stone ash, lime or fly ash commonly used as fillers on hotmix are particles passed $0.075 \mathrm{~mm}$. Graphene is an easily obtainable material in nature and is a single layer or can also be an excellent triple layer to strengthen composite materials. The thickness possessed by graphene monolayer ranges from $0.4 \mathrm{~nm}$ and tensile strength of $1 \mathrm{TPa}$.

\section{RESEARCH METHODS}

The materials used are asphalt pen. 60/70, coarse aggregate, fine aggregate and graphene. Eswariah [5], graphene is obtained from graphite by electrochemical and mechanical liquid exfoliation (EMLE) methods. The resulting Graphene EMLE is silenced until the froth inside the tube disappears. Graphene EMLE mixed with asphalt penetration 60/70 with a variation of $3.5 \% ; 4 \%$ and $4.5 \%$. Asphalt and graphene mixture variants are mixed into specimen hotmix variants that have known optimum asphalt content.

Graphite lowers marshall stability values so that the application of graphite to paved mixtures is not widely developed (Kök et al., 2017)[4].

\section{RESULTS AND DISCUSSION}

Asphalt pen. 60/70 mixed with variant graphene is penetration tested according to SNI-062456[6], the data in Figure 2.

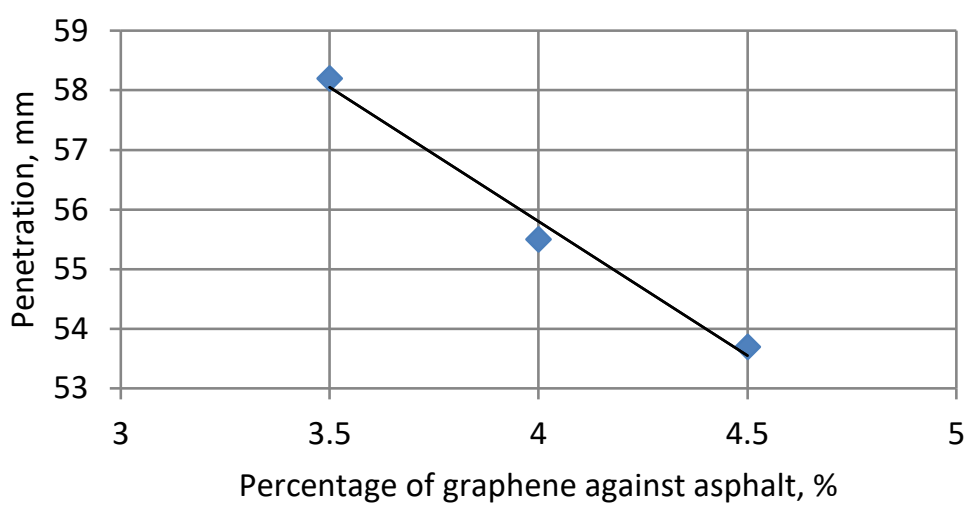

Figure 1 Relationship of graphene percentage with asphalt penetration value.

Graphene is a honeycomb-like sheet of carbon bonds and has a wide surface area. So that the bond between carbon aton sheets on graphene and asphalt is very strong, this is what adds to the strength of asphalt and decreases the penetration value of asphalt. From Figure 2, it is seen that graphene decreases the penetration of asphalt and makes asphalt penetration smaller, with graphene $3.5 \%$ asphalt penetration $58 \mathrm{~mm}$, with graphene $4 \%$ asphalt penetration 55.5 $\mathrm{mm}$ and dngan graphene $4.5 \%$ asphalt penetration $53.6 \mathrm{~mm}$. A small penetration value is 
predicted to increase the stability value of hotmix. Penetration indicates the degree of hardness of asphalt.

Penetration of reverse function with a degree of hardness, higher penetration describes a softer consistency, while a lower penetration value indicates the harderness of asphalt (Yuniarti, 2015) [7]. Asphalt consists of macro hydrocarbon elements with sulfur, oxygen, nitrogen and other chemical elements affected by the manufacturing process (Read \&Whiteoak, 2003) [8], as in Table 1. Graphite (processed with EMLE into graphene) on a microscopic scale consists of a base sheet of bonded carbon atoms (Rampe, 2015). [9].

Table 1 Chemical Composition on Asphalt

\begin{tabular}{lc}
\hline \multicolumn{1}{c}{ Component } & Persentage (\%) \\
\hline Carbon & $82-88$ \\
Sulfur & $0-6$ \\
Oksigen & $0-1.5$ \\
Hidrocarbon & $8-11$ \\
Nitrogen & $0-1$ \\
\hline
\end{tabular}

Reference: Read \&Whiteoak (2003).

Incorporating graphene into asphalt means increasing the percentage of carbon and making its carbon greater than $(82-88) \%$, increasing the carbon percentage decreases the penetration value of asphalt and increases asphalt hardness. Addition of graphene into asphalt pen. 60/70 makes asphalt with more plastic characteristics so that it becomes asphalt pen. 50/60.

Optimum asphalt content result with the influence of graphene addition in Figure 3.

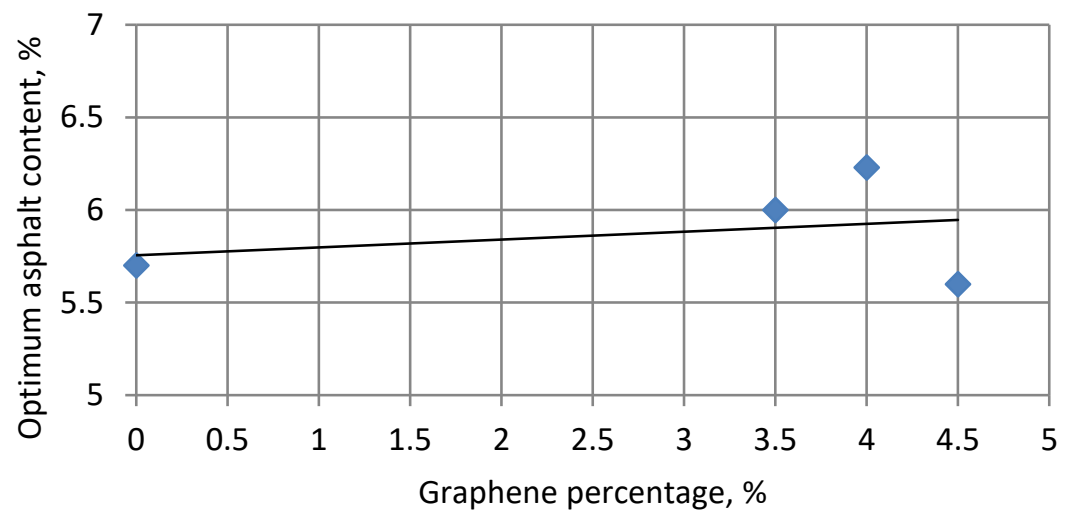

Figure 2 Relationship of graphene addition with optimum asphalt content

From Figure 2 it appears that the use of graphene increases the value of optimum asphalt levels insignificantly. The percentage of graphene addition of $3.5 \%$ increased the optimum asphalt content by $5.26 \%$, the addition of graphene $4 \%$ increased the optimum asphalt content by $9.30 \%$ and the addition of graphene $4.5 \%$ lowered the optimum asphalt content by $1.75 \%$. The optimum asphalt content is more economic.

The relationship of graphene usage with stability as shown in Figure 3. 


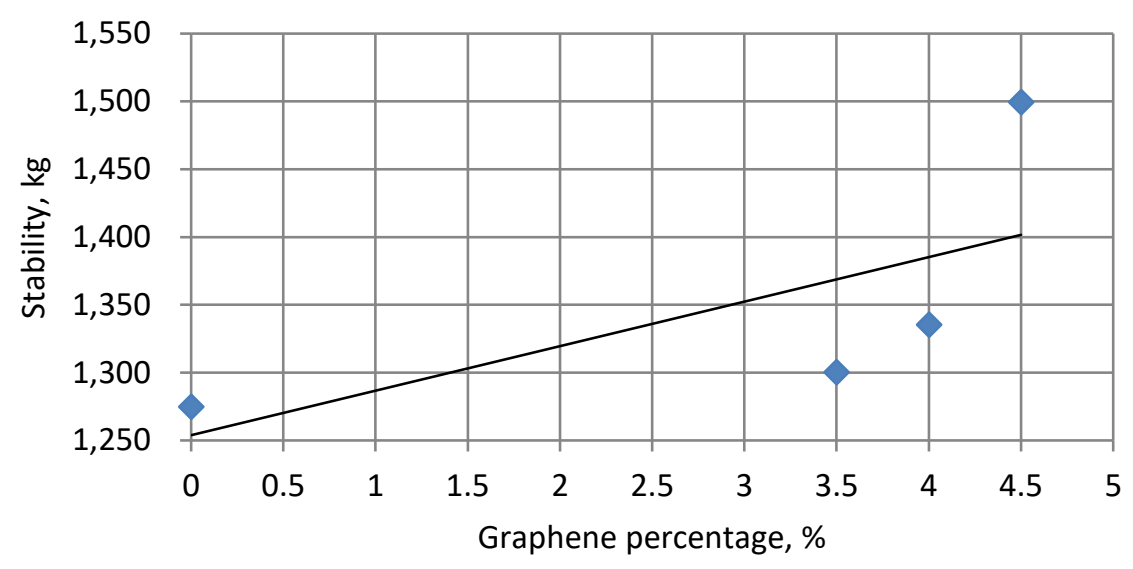

Figure 3 Graph of stability relationship with graphene percentage

Stability demonstrates the ability to withstand deformation due to traffic loads without deformation. Graphene fiber sheet structure fills cavity interconnection in hotmix. The interconnection of hotmix cavities filled by a collection of fiber sheets glued by bitumen leads to an increase in the stability value of hotmix. Fiber sheet on graphene is not only as a filler but more than that as nano-fillers and also as nano-reinforces. Addition of graphene up to $4.5 \%$ improves stability from $1,260 \mathrm{~kg}$ to $1,480 \mathrm{~kg}$.

Graphene as an easily obtainable material in nature, in this study using triple-layer graphene (the result of emle method) is very good to strengthen the composite material hotmix AC-BC. Graphene that is nano-material that passes \# no. 200 in the form of fiber sheet can fill a finer cavity interconnection than other types of fillers. Fiber sheet material in nano-graphene has greater tensile strength (1 TPa). It is this graphene strength that is very supportive to improve the stability of AC-BC hotmix because the stability characteristics of the AC-BC hotmix are the accumulation of press and pull properties of the forming material. This nano-graphene fiber sheet is perfect when referred to as a super-filler for AC-BC hotmixes.

From Figure 3 it is also seen that the stability of $\mathrm{AC}-\mathrm{BC}$ hotmix tends to experience a significant increase with the addition of graphene percentage. Graphene addition percentage $3.5 \%$ stability increase $1.96 \%$, graphene addition $4 \%$ stability increase $4.71 \%$ and graphene addition $4.5 \%$ stability increase $13.65 \%$. In accordance with Ziari et al, 2014[10] adding carbon nanotubes CNT (carbon conditions equivalent to graphene) to hotmix asphalt (HMA) using asphalt pen 60/70 indicates that the addition of CNT can improve the stability value of HMA marshalls. According to Bharathi et al (2018)[11] conducting research on the effect of the addition of graphene nanoplatelet (GNP) on the characteristics of macadam penetration layers using asphalt penetration 40/50 shows that the addition of GNP can increase the stability value of marshalls. According to Hafeez et al (2019)[12] adding graphene nanoplatelet (GNP) to $60 / 70$ penetration asphalt mixed at a constant temperature of $158^{\circ} \mathrm{C}$ for 10 minutes indicates that the addition of GNP can increase asphalt hardness and increase tensile strength. Graphene improves mechanical properties that improve material strength for construction (Young et al., 2012)[13].

According to Le et al, 2016[14], there are two forms of CNT structures, namely single-wall CNT and multi-wall CNT which can be seen in Figure 5. 


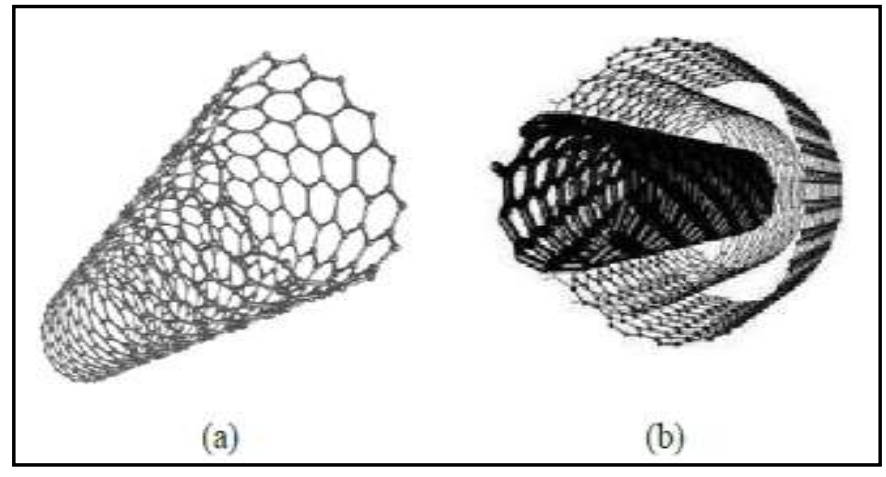

Figure 4. Structure of Carbon Nanotube (a) Single-Wall CNT and (b) triple-Wall CNT.

Triple layer (as in Figure 4) on carbon graphene structure serves as filler that fills the cavity between aggregate grains on hotmix and at the same time serves as nano-fiber that provides additional hotmix strengthening. The addition of graphene (with EMLE process) containing triple-wall carbon layer adds carbon elements to the asphalt thus increasing the hardness value of asphalt and improving the stability of AC-BC hotmix.

The relationship of graphene usage with flow as shown in Figure 5. Flow shows the amount of deformation that occurs in the hotmix layer due to withstanding the load it receives. Small flow tends to produce rigid and vibrating pavements, while high flow values make pavement elastic.

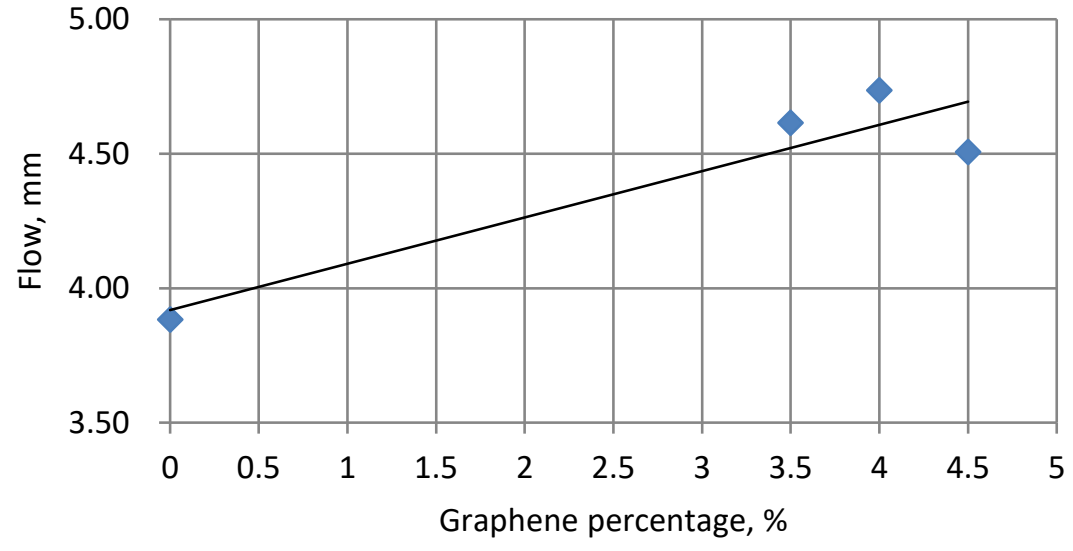

Figure 5 Relationship of graphene percentage with flow.

From Figure 5 it appears that the flow value has increased but still enters the characteristics of the specification. Graphene addition percentage $3.5 \%$ flow increase $18.81 \%$, graphene addition $4 \%$ flow increase $22.16 \%$ and graphene addition $4.5 \%$ flow increase $16.23 \%$.

Nano-material graphene in the form of fiber sheet that has a very wide surface $(\mathrm{m} 2 / \mathrm{gr})$. The accumulation of asphalt with nano-graphene surfaces causes graphene as a reinforcement and as a filler. Flow is more influenced by the adhesion properties of asphalt and graphene materials. The flexibility properties of bitumen mixed with graphene and the surface area of graphene fibers, this is a rarity. Add graphene in AC-BC can improve stability and at the same time increase flow / elasticity.

The increase in stability value is due to the perpendicular force of fiber graphene fiber. The dactility test that does not undergo major changes is due to the direct tensile force of graphene fibers in AC-BC. Dactility test results with graphene $0 \%, 3.5 \%, 4 \%$ and $4.5 \%$ the average result is $>100 \mathrm{~cm}$. 
The relationship of graphene use with VIM as shown in Figure 7.

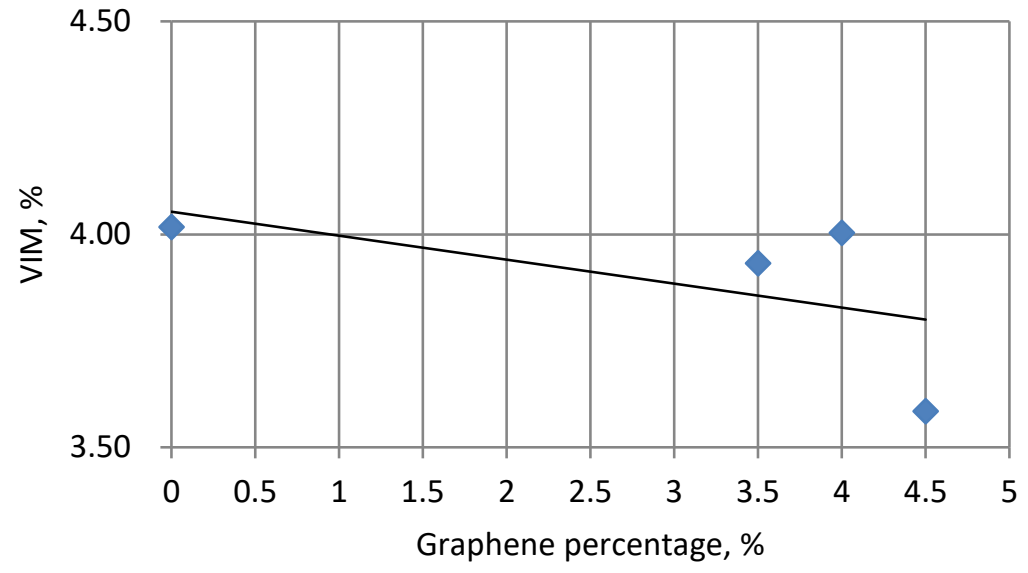

Figure 6 Relationship of graphene percentage with VIM.

From Figure 6 it appears that the VIM value changes but still enters the specification. Graphene addition percentage $3.5 \%$ VIM decrease $2.24 \%$, graphene addition $4 \%$ VIM decrease $0.50 \%$ and graphene addition $4.5 \%$ VIM decrease $10.95 \%$. The nano-graphene thickness of $0.4 \mathrm{~nm}$ does not affect the filling of space in the interconnection of hotmix cavities thus lowering the VIM value. The addition of graphene does not significantly decrease VIM. Single layer or triple layer graphene fills VIM area and also fills bitumen film thickness (BTF) on AC-BC hotmix, illustration as in Figure 7. Graphene inside VIM serves as a filler while inside the film thickness bitumen serves as reinforced.

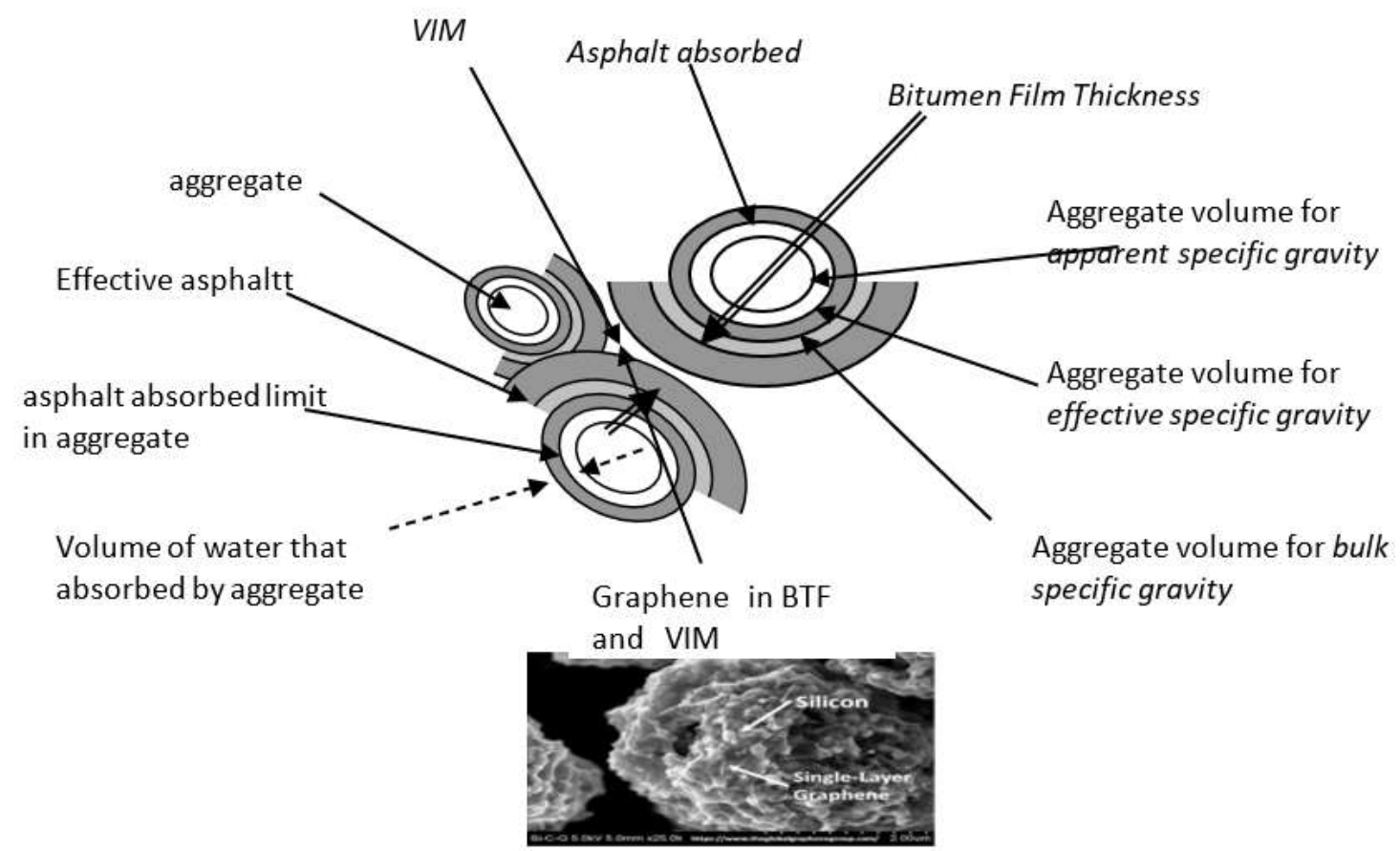

Figure 7. Carbon and silicon atoms in graphene that fill the VIM and BTF areas. [modification 15].

The relationship of graphene use with VFA as shown in Figure 8. 


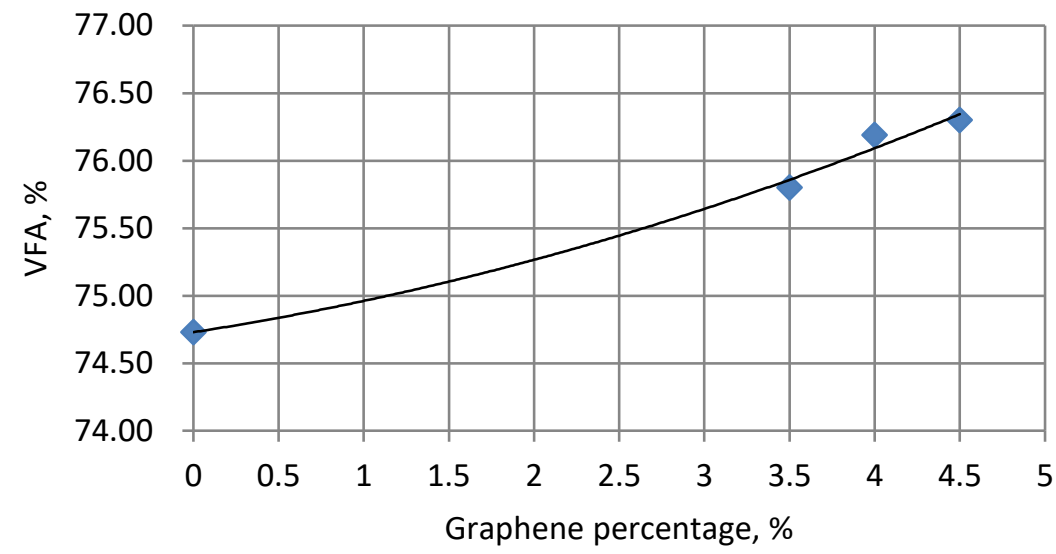

Figure 8. Relationship of graphene percentage with VFA.

From Figure 8 it appears that an insignificant increase in VFA values is associated with an increase in graphene percentage. Graphene addition percentage $3.5 \%$ increase VFA $1.43 \%$, graphene addition $4 \%$ increase VFA $1.95 \%$ and graphene addition $4.5 \%$ increase VFA 2.10 $\%$. Graphene with a nano-material size of $0.4 \mathrm{~nm}$ can fill the smaller air cavity graphene bonded with asphalt also fills more air cavities at a finer cavity size. It is this factor that causes the increased use of graphene percentage does not greatly increase the air cavity filled with asphalt. Addition of graphene increases VFA

The relationship of graphene use with VMA as shown in Figure 9.

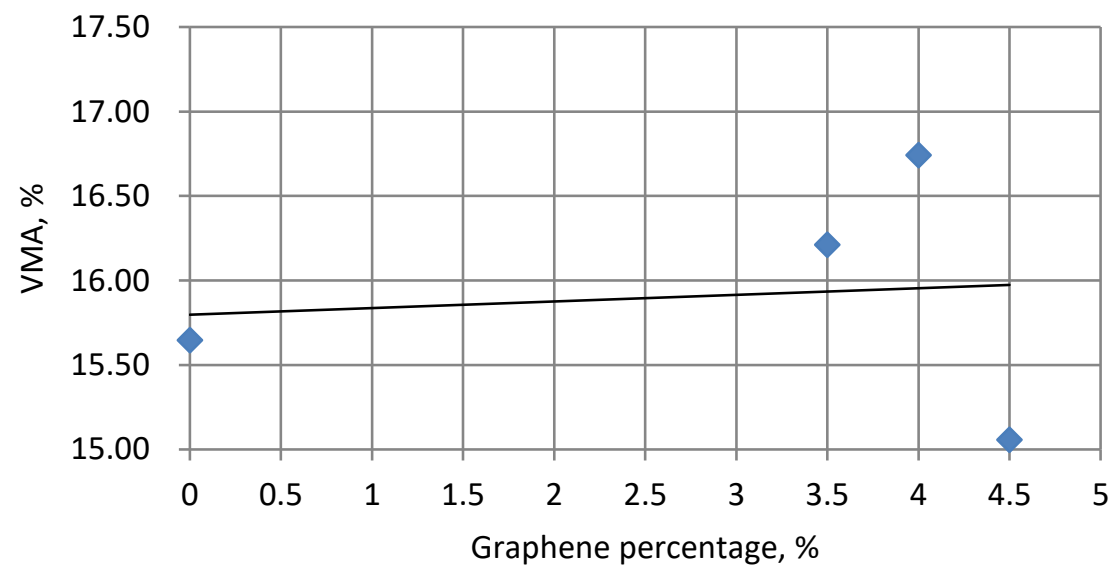

Figure 9. Relationship of graphene percentage with VMA.

From Figure 9 it appears that an insignificant increase in VMA values is associated with an increase in graphene percentage. Graphene addition percentage $3.5 \%$ increase VMA $3.58 \%$, graphene addition $4 \%$ increase VMA $6.96 \%$ and graphene addition $4.5 \%$ decrease VMA 3.77 $\%$.

\section{CONCLUSION}

Effect of the addition of graphene on the characteristics of AC-BC characteristics are graphene is a honeycomb-like sheet of carbon bonds and has a wide surface area. So that the bond between carbon atom sheets on graphene and asphalt is very strong, this is what adds to the strength of asphalt and decreases the penetration value of asphalt from $60 \mathrm{~mm}$ to $53.6 \mathrm{~mm}$, decreases $1.75 \%$ the value of optimum asphalt content, improves stability from 1,260 kg to 
$1,480 \mathrm{~kg}$, increased flow from $3.80 \mathrm{~mm}$ to $4.50 \mathrm{~mm}$. Add graphene in AC-BC can improve stability and at the same time increase flow / elasticity, decrease VIM $10.95 \%$, increases VFA $2.10 \%$, and decreases VMA $3.77 \%$.

\section{ACKNOWLEDGEMENTS}

The author thanked the manager of the highway laboratory, Amun Amri as manager of Chemical engineering materials laboratory and Ali Novia, Engineering Faculty, Riau University.

\section{REFERENCES}

[1] Aravind, S.d., Construction of Porous Asphalt Pavement Using Graphene. Journal of Civil Engineering

[2] Ranjbar, N, et al., Graphene nanoplatelet-fly ash based geopolymer composite. Cement and Concrete Research, 2015. 76: p. 222-231.

[3] Bina Marga, Road and Bridge General Specifications, 2010, section 6.3.

[4] Kök, B., Yilmaz, M., \& Erkuş, Y., 2017, Effects of Graphite on Mechanical Properties of Stone Mastic Asphalt Pavement, Journal of Civil Engineering and Management, 23(8), 1013-1020, https://doi.org/10.3846/13923730.201 7.1374302.

[5] Eswaraiah, V., K. Paton, C. Backes, A. Harvey, R. Smith, J. Mc Cauley dan J.Coleman, Turbulence-assisted shear exfoliation of graphene using household detergent and a kitchen blender, 2014. Nanoscale. DOI :10.1039/C4NR03560G.

[6] Bina Marga. (1991). SNI-06-2456. Penetration Testing Method of Bitumen Materials. Jakarta : Pustran Balitbang Pekerjaan Umum.

[7] Yuniarti, R, 2015, Asphalt Modification With Pine Sap and Fly Ash to Produce Bio-Asphalt, Journal of Technology \&Environment Science, 1(2), 1-7.

[8] Read, Dr. J., \& Whiteoak, Mr. D., 2003, The shell Bitumen Handbook, London : Thomas Telford.

[9] Rampe, M. J., 2015 Conversion of Coconut Shell Charcoal into Carbon Electrodes, Chemistry Progress, 8(2), 77-86.

[10] Ziari, H., Farahani, H., Goli, A., \& Galooyak, S. S., 2014, The Investigation of the Impact of Carbon Nanotube on Bitumen and HMA Performance, Petroleum Science and Technology, 32, 2102-2108, https://doi.org/10.1080/10916466.2013.763827.

[11] Bharathi, B., Jeevan, N., Shekhar, P. R., Khan, S., \& Mahadeva, B., 2018, Performance Evaluation \& Measurement of Heat from the Bituminous Surface by the Addition of Graphene, International Journal for Scientific Research \& Development, 6(4), 991-994.

[12] Hafeez, M., Ahmad, N., Kamal, M. A., Rafi, J., Ul-haq, M. F., Jamal, J., \& Nasir, M. A., 2019, Experimental Investigation into the Structural and Functional Performance of Graphene NanoPlatelet (GNP)-Doped Asphalt, Applied Sciences, 9(4), https://doi.org/10.3390/app9040686.

[13] Young, R. J., Kinloch, I. A., Gong, L., \& Novoselov, K. S., 2012, The Mechanics of Graphene Nanocomposites: A Review, Composites Science and Technology, 72(12), 1459-1476, https://doi.org/10.1016/j.compscitech.2012.05.005.

[14] Le, J., Marasteanu, M., \& Turos, M., 2016, Graphene Nanoplatelet (GNP) Reinforced Asphalt Mixtures: A Novel Multifunctional Pavement Material, IDEA Program Final Report NCHRP 173.

[15] M. Shalahuddin dkk, 2015, Clay Filler Performance on Hotmix AC-WC. Konteks Proceedings 5 